\title{
The Japanese returnee experience: factors that affect reentry
}

\author{
Tomoko Yoshida $^{\mathrm{a}}$, David Matsumoto ${ }^{\mathrm{b}, *}$, Tsuyoshi Akiyama ${ }^{\mathrm{c}}$, \\ Naoko Moriyoshi ${ }^{\mathrm{d}}$, Atsushi Furuiye ${ }^{\mathrm{e}}$, Chikako Ishii $^{\mathrm{f}}$, \\ Brenda Franklin ${ }^{\mathrm{b}}$

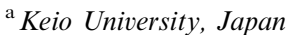 \\ ${ }^{\mathrm{b}}$ Department of Psychology, Culture and Emotion Research Laboratory, San Francisco State University, \\ 1600 Holloway Avenue, San Francisco, CA 94132, USA \\ ${ }^{\mathrm{c}}$ NTT Kanto Medical Center, Japan \\ ${ }^{\mathrm{d}}$ University of Pennsylvania, USA \\ ${ }^{\mathrm{e}}$ Roots International, Japan \\ ${ }^{\mathrm{f}}$ TELL Community Counseling Service, Japan
}

\begin{abstract}
Although the number of Japanese children raised overseas has been increasing and many steps have been taken to ease reentry for them, the consequences of these efforts are not clear. Japanese parents who sojourn abroad with their children are still left to a trial and error approach when it comes to their children's education and socialization. This study examined what factors predict the various social and psychological outcomes of the "returnee experience." Based on previous work, 27 dependent variables were employed to assess the types of social and psychological consequences experienced by returnees; they were reduced to nine factors by factor analysis. Also, 31 variables that previous literature suggested influenced these experiences were measured; factor analysis reduced them to 10 factors. A backward multiple regression was then conducted on each of the nine dependent factors. Results showed that communication with parents, recency of return and special provisions were key to capturing positive outcomes. (C) 2002 Elsevier Science Ltd. All rights reserved.
\end{abstract}

Keywords: Reentry; Returnees (kikokushijo); TCK; Global nomad; Culture shock; Adjustment

*Corresponding author. Tel.: + 1-510-236-9171, fax: + 1-510-217-9608.

E-mail address: dm@sfsu.edu (D. Matsumoto). 


\section{Introduction}

The number of children raised outside their passport countries has increased significantly over the past 30 years. In Japan alone, the number of children being educated abroad has increased over eleven-fold compared to 1975 (Ministry of Education, 1999). While some returnees report difficulty readjusting to Japan, others find the transition easy (Fujiwara et al., 1985).

Previous studies have examined what variables account for these differences, but they were limited because many changes have occurred since they were conducted. For example, the number of Japanese schools overseas has increased from 26 in 1971 to 85 in 1990; supplementary schools from 22 in 1971 to 146 in 1990 . The amount of information available to parents has also increased substantially (Kaigaishijo Kyouikushi Hensan Iinkai, 1991). Perhaps the most influential factor was the implementation of special quotas for returnees by many prestigious universities in the mid-1980s. Returnees were no longer "victims" with Japanese language handicaps, but "elites" who gained relatively easy entry into prestigious universities and subsequently into prestigious companies (Goodman, 1990).

Since these changes have occurred, there has not been a reexamination of the factors that predict Japanese returnees' readjustment to Japan. Moreover, prior studies have focused on school age returnees even though evidence has suggested that the returnee experience is not short-lived. The current study examined which factors can predict the various social and psychological outcomes returnees experience across the age spectrum.

\subsection{Research on reentry issues of Japanese returnees}

\subsubsection{Social and psychological outcomes of the returnee experience}

Kidder (1992) reported that many returnees felt different from their peers after returning to Japan. Many felt that they were "Physically Marked" because their fashion, hair, make-up, ways of talking and walking were different. "Behavioral Signs" such as eye contact, facial expressions and gestures often "gave them away" as returnees. "Interpersonal Styles" were also different, with returnees indicating that they had problems with Japanese "Manners of Speaking," especially with keigo (honorifics). Kidder claimed that in response to being "different," some returnees chose to hide the fact that they were returnees while others adopted "chameleon-like techniques to blend in with the occasion and change colors according to context" (p. 390).

Minoura (1988) reported that the two most commonly cited causes of problems among returnees and their peers came from differences in their interpersonal styles, specifically in their patterns of self-assertion (jibun no dashikata) and the relationship between the individual and the group (kojin to shuudan no kankei). Returnees, especially the ones who lived in Western cultures, had a tendency to be direct and assert their opinions freely. Their Japanese peers felt that this was crass and inconsiderate. 
In response to being different, many returnees conformed. In fact, Takeuchi, Imahori and Matsumoto, 2001 study of returnees' criticism style found that they were even more indirect than their Japanese counterparts, overcompensating for differences in communication styles. Ebuchi (1988) reported that unless they conformed to the group, elementary school returnees became objects of bullying. Furthermore, some junior high school students reported that when external pressures to conform were very strong, they adapted on the surface while internally maintaining their individuality. For some returnees, this discrepancy has led to a conflict between their internal and external self. Thus, many studies have reported identity issues as being central to the returnee experience (Kanno, 2000; Onoda, 1988).

Other returnees, however, return to Japan with ease. Fujiwara et al.'s (1985) study revealed three types of returnees. The first group tried hard to adjust to Japan and was conscious of the differences between Japan and their host country. Although they were not necessarily completely satisfied with their current situation, they tried hard to fit in. The second group consisted of children who adjusted back to life in Japan without any particular effort. The third group consisted of those who experienced adjustment problems. They felt like strangers in their own land and were very conscious that they were returnees.

\subsubsection{Duration of reentry issues}

Kobayashi et al. $(1978,1983)$ surveyed 650 Japanese children, and found that most $(90.5 \%)$ adjusted back to Japanese school life within a year. To investigate whether deeper issues emerged after the initial phase of adjustment, Minoura (1988) conducted a 10-year longitudinal study of 75 returnees' psychosocial aspects of adjustment, and reported that for many returnees who had lived abroad for an extended time, the first year in Japan consisted of adjustment on the surface level. Between the second and third years, they started to realize that behavioral differences were rooted in deeper cultural differences such as values or ways of thinking. Tsukamoto's (1990) study of 303 mothers of returnees also showed that although returnees adjusted to their physical/biological environment fairly rapidly, usually within 18 months, their social adjustment in terms of self-concept tended to take much longer. White (1988) noted "we have seen that it is the workplace that most adamantly resists the returnees' reentry" (p. 111). These results concurred with Bock's (1977) assertion that there are at least three levels in people's adaptation to a new situation: (1) physical/environmental adaptation, (2) social adaptation (human relationships), and (3) internal (self) adaptation.

\subsubsection{Experiential and demographic characteristics}

A number of studies have examined what factors predict readjustment to Japan for Japanese returnees. Takahagi et al. (1982), for instance, showed that length of sojourn significantly affected various factors such as what parents took into consideration while abroad and upon return to Japan, children's lifestyles while abroad and upon return to Japan, and the children's impression of their experience 
returning to Japan. Gender differences also emerged, with girls scoring lower on the culture shock scale than boys (see also Gerner \& Perry, 2000).

Other studies have found additional factors that affect the "returnee experience." Minoura (1991) reported that children who sojourned and returned between the ages of 9 and 14-15 and stayed there for 4 or more years were more likely to experience adjustment problems. Fichtner (1988) found that those who had lived in Asian cultures had a higher ease of social re-entry than those who had lived in Western cultures. Tamura and Inamura (1987) highlighted the importance of the family's role, especially the mother's, in shaping the child's experience while abroad and upon return to Japan, suggesting that children with mothers who had problems adjusting to the host culture often experienced problems with reentry. They also pointed out that overly constrictive school environments made reentry more difficult.

Most studies have only looked at the negative consequences of the "returnee experience" on children in the elementary, junior and senior high schools. Furthermore, these studies were conducted in the 1970s and 1980s, precluding those who returned after the institution of special quotas for returnees at prestigious universities. The present study addressed these issues by: (1) targeting a wider age range of returnees (12-71), (2) examining a wider range of social and psychological outcomes (not only negative ones), and (3) collecting data over 10 years after the institution of special quotas for returnees at prestigious universities.

\subsubsection{Overview of the present study}

To examine the various facets of the returnee experience, we began by asking the following question.

RQ1: What are the social and psychological outcomes of the "returnee experience"?

Previous studies revealed that "feeling different" was a key feature of being a returnee. Hypothesis 1, therefore, examined whether Feeling Different would emerge as a core of the "returnee experience." Hypothesis 2 tested whether special provisions for returnees, including special quotas at prestigious universities, were likely to be associated with perceived advantages and/or stigma and identified as a salient outcome for returnees.

Hypothesis 1. Feeling different is a key factor in the returnee experience.

Hypothesis 1a. The social consequences of being different are rejection and acceptance by peers.

Hypothesis 1b. The personal attitudes regarding feeling different are either conforming to or not conforming to the mainstream culture.

Hypothesis 1c. The psychological consequences of being different are adjustment problems and positive or negative assessment of the returnee experience.

Hypothesis 2. The consequences of the special provisions for returnees are perceived advantages and/or stigma. 
RQ2: Are there demographic and experiential characteristics that shape the experiences of returnees while abroad and immediately upon return to Japan?

Research question 2 examined whether particular demographic and experiential characteristics played a formative role in the returnees' experiences. We were especially interested in seeing whether the various provisions made for the returnees played a significant role.

RQ3: Do the factors identified in RQ2 predict the outcomes identified in RQ1?

Hypothesis 3 examined whether the various factors identified in previous studies were likely to be predictors of the social and psychological outcomes identified in this study. Hypothesis 4 tested whether the special provisions made for returnees were likely to predict the subsequent social and psychological consequences.

Hypothesis 3. Age (present, at time of departure and return), sex, length of sojourn, type of school attended upon return to Japan, place of sojourn, and relationship with parents will predict various outcomes of the returnee experience.

Hypothesis 4. Special provisions (schools attended abroad, while in Japan, special quota, etc.) will predict the subsequent returnee experience.

\section{Methodology}

\subsection{Participants}

Returnees were individuals who spent at least 2 years abroad between the ages 5 and 18 due to their parents' occupation. 512 (male $=182$; female $=315$; 15 did not report) completed the questionnaire. Their ages ranged from 12 to 71 with the mean being 20.15 and the mode 17 .

\subsection{Instrument}

A seven-page, 74-item questionnaire was employed. Thirty-five items were included as predictors while the remaining 39 measured social and psychological outcomes. The predictors were based on previously cited experiential and demographic variables that presumably defined the returnee experience, and were organized around the following categories: defining characteristics of the sojourning experience, communication with parents and others, and type of school entered immediately upon return to Japan (see Table 2 for the specific items). The dependent variables were also based on previous studies, and were organized around the following categories: effort to conform, relationships with peers, readjustment difficulties, feeling accepted, returnee advantage, satisfaction/dissatisfaction/impact of the returnee experience (see Table 1 for specific items). All but four items were on an ordinal (four-point) scale, which was chosen to counterbalance a possible Japanese tendency to avoid extreme responses and gravitate toward the mid-point 
Table 1

Social and psychological outcomes

\begin{tabular}{lll}
\hline $\begin{array}{l}\text { Tentative name } \\
\text { for factor poles }\end{array}$ & Items & $\begin{array}{l}\text { Factor } \\
\text { loading }\end{array}$ \\
\hline
\end{tabular}

DV Factor 1: Feeling Different

Eigenvalue $=3.502$
Presently feels that they are being treated differently or are being perceived differently because of being a returnee.

Upon return to Japan, felt that they were treated differently or were being perceived differently because they were returnees.

Presently, senses a difference in the way of thinking between themselves and other Japanese.

Immediately upon return to Japan, sensed a difference in the way of thinking between themselves and other Japanese.

Glad that they were born Japanese.

Had difficulty adjusting when they first returned to Japan.

Listed many things they liked about their overseas experience.

Listed many things they enjoyed about being a returnee.

Listed many things they didn't like about their overseas experience.

Listed many things they didn't enjoy about being a returnee.

Listed many activities they were involved in (outside of school and work) after returning to Japan.

DV Factor 3:

Adjustment

Difficulties

Eigenvalue $=2.191$

Had difficulty adjusting when they first returned to Japan.

Felt that they were excluded from a group because of being a returnee. Experienced uncertainty, depression or psychosomatic symptoms immediately upon return to Japan.
DV Factor 4:

Acceptance

Eigenvalue $=1.498$

DV Factor 5:

Advantage

Eigenvalue $=1.414$
Enjoyed special privileges because of being a returnee.

Has felt short-changed due to being treated like a returnee.

Immediately upon return to Japan, felt that there was someone who was willing to accept them as they were.

Immediately upon return to Japan, sensed a difference in the way of thinking between themselves and other Japanese.

Upon return to Japan, felt that they were treated differently or perceived as being different because they were returnees.

Presently feels that there is someone who is willing to accept them as they are.

Immediately upon return to Japan, felt that there was someone who was willing to accept them as they were.

Is presently trying to conform to the people around them.

0.678

0.619

0.585

$-0.410$

0.401

$-0.392$

0.846

Presently feels that they are able to take advantage of their returnee experience outside of school or work.

Presently feels that they are able to take advantage of their returnee experience at school or at work.

Has enjoyed special privileges because of being a returnee.

Listed many activities they were involved in (outside of school and work) after returning to Japan.

Is content with present self.

0.768

0.408

0.326

0.838

DV Factor 6: Self- Would like to take their children with them if they were to be assigned to go overseas. 
Table 1 (continued)

\begin{tabular}{|c|c|c|}
\hline $\begin{array}{l}\text { Tentative name } \\
\text { for factor poles }\end{array}$ & Items & $\begin{array}{l}\text { Factor } \\
\text { loading }\end{array}$ \\
\hline Eigenvalue $=1.297$ & Is happy to have lived abroad in their youth. & 0.734 \\
\hline DV Factor 7: & Feels that they can live anywhere in the world. & -0.764 \\
\hline Negativity & Has felt short-changed due to being treated like a returnee. & 0.381 \\
\hline Eigenvalue $=1.170$ & $\begin{array}{l}\text { Is presently trying to conform to the people around them. } \\
\text { Is content with present self. }\end{array}$ & $\begin{array}{r}0.370 \\
-0.342\end{array}$ \\
\hline $\begin{array}{l}\text { DV Factor 8: } \\
\text { Group Conformity }\end{array}$ & $\begin{array}{l}\text { Tried to conform to the people around them when they first } \\
\text { returned to Japan. }\end{array}$ & 0.622 \\
\hline Eigenvalue $=1.131$ & $\begin{array}{l}\text { Presently feels excluded from a group because of being a returnee. } \\
\text { Has felt excluded from a group because of being a returnee. } \\
\text { Has felt short-changed due to being treated like a returnee. }\end{array}$ & $\begin{array}{l}-0.581 \\
-0.435 \\
-0.311\end{array}$ \\
\hline \multirow[t]{2}{*}{$\begin{array}{l}\text { DV Factor 9: } \\
\text { Impact } \\
\text { Eigenvalue }=1.059\end{array}$} & $\begin{array}{l}\text { Has felt that their worldview has changed since returning to Japan. } \\
\text { Immediately upon return to Japan, sensed a difference in the way of } \\
\text { thinking between themselves and other Japanese }\end{array}$ & $\begin{array}{l}0.859 \\
0.338\end{array}$ \\
\hline & $\begin{array}{l}\text { Presently, senses a difference in the way of thinking between } \\
\text { themselves and other Japanese. }\end{array}$ & 0.329 \\
\hline
\end{tabular}

Note: The items have been transformed from their original question form into statements to ease interpretation.

(Chen, Lee, \& Stevenson, 1995; Iwawaki \& Cowen, 1964; Zax \& Takahashi, 1967). The scale was anchored 1: no (iie), 2: a little (sukoshi), 3: quite a bit (kanari), 4: very (hijooni). The remaining items were open-ended questions with 10 blanks, which were coded by the number of blanks filled out by the respondents.

\subsection{Procedure}

Data were obtained from high school and university student returnees, and nonstudents. High school students were recruited from two high schools with a large number of returnees and 16 high schools with smaller numbers of returnees, all from urban and rural areas of Japan. After obtaining permission from the principals, packages containing the questionnaires were sent to the schools in November 1997. The packets contained: (1) a cover letter that introduced the purpose of the study and ensured confidentiality, (2) the questionnaire, (3) a self-addressed stamped envelope, and (4) a small white envelope. Subjects were instructed to complete the questionnaires at their leisure and return them in the enclosed self-addressed stamped envelope. They were also instructed to write their name and address on the small white envelope and to send it back to us with the questionnaire. Upon receipt, a small token of appreciation (a 500 yen telephone card) was placed in the small white envelope and sent to the respondents. One hundred and fifteen students from the high schools with fewer returnees, and 100 from high schools with a large 
Table 2

Experiential and demographic characteristics of returnees

\begin{tabular}{lll}
\hline $\begin{array}{l}\text { Tentative name } \\
\text { for factor poles }\end{array}$ & Items & Factor \\
\hline
\end{tabular}

IV Factor 1:

Japanese School

Eigenvalue $=4.912$

While abroad, spoke Japanese at school.

0.895

While abroad, attended a Japanese school the longest. $\quad 0.855$

While abroad, spoke English at school. $\quad-0.652$

While abroad, did not attend a Japanese school. $\quad-0.568$

While abroad, did not attend a local school. 0.558

While abroad, did not attend a hoshuu-kou (supplementary school). $\quad 0.472$

While abroad, spent the largest amount of time in a country other $\quad 0.450$

than the USA.

While abroad, spoke Japanese in the community. 0.416

While abroad, spoke English in the community. -0.325

While abroad, was brought up to be familiar with the local culture. -0.334

IV Factor 2:

International

School

Eigenvalue $=2.823$

IV Factor 3:

Extensive Stay

Eigenvalue $=2.299$

IV Factor 4:

Communication

with Parents

Eigenvalue $=2.091$

IV Factor 5:

Special Provisions

Eigenvalue $=1.979$

IV Factor 6:

Recency of Return

Eigenvalue $=1.621$

IV Factor 7:

Older Sojourning

Experience

Eigenvalue $=1.373$
While abroad, attended an international school the longest.

0.842

While abroad did not attend an international school.

$-0.808$

While abroad, spent the largest amount of time in a country other $\quad 0.610$

than the USA.

While abroad, did not attend a local school.

0.608

While abroad, spoke English in the community.

$-0.540$

While abroad, did not attend a Japanese school.

$-0.407$

While abroad, did not attend a hoshuu-kou (supplementary school). $\quad 0.405$

Lived overseas for a long time.

0.816

Was older when they first went abroad.

$-0.783$

0.712

While abroad, spoke to your parents about many things. 0.752

While abroad, consulted parents when they had problems. $\quad 0.709$

Before returning to Japan, received an explanation from their $\quad 0.606$

parents regarding the move.

Prior to leaving Japan, received an explanation from their parents

0.562

regarding the move.

Immediately upon return to Japan, was enrolled in a class with

0.867

many returnees.

Was, at some point, enrolled in a class with many returnees.

0.811

Immediately upon return to Japan, was not enrolled in a class with -0.673

special provisions for returnees.

Returned to Japan a long time ago.

$-0.781$

Is older.

$-0.712$

0.652

Was older when they last returned to Japan. $\quad 0.809$

Is older. $\quad 0.557$

While abroad, was brought up to be familiar with the local culture. $\quad-0.489$

Was older when they first went abroad.

0.312 
Table 2 (continued)

\begin{tabular}{llr}
\hline $\begin{array}{l}\text { Tentative name } \\
\text { for factor poles }\end{array}$ & Items & $\begin{array}{c}\text { Factor } \\
\text { loading }\end{array}$ \\
\hline $\begin{array}{l}\text { IV Factor 8: } \\
\text { International } \\
\text { Community }\end{array}$ & $\begin{array}{l}\text { Prior to graduating from high school, did not live apart from their } \\
\text { parents for more than one year. }\end{array}$ & 0.609 \\
Eigenvalue $=1.215$ & $\begin{array}{l}\text { While abroad, spoke English at school. } \\
\text { While abroad, spoke English in the community. }\end{array}$ & 0.487 \\
& $\begin{array}{l}\text { Immediately upon return to Japan, was not enrolled in a class with } \\
\text { special provisions for returnees. }\end{array}$ & 0.406 \\
& While abroad, was brought up to be familiar with the local culture. & -0.305 \\
IV Factor 9: & While abroad, did not attend a juku. & 0.711 \\
Limited Resources & While abroad, consulted people other than their parents when & -0.551 \\
Eigenvalue =1.164 & they had problems. & 0.308 \\
& Returned to Japan a long time ago. & -0.739 \\
IV Factor 10: & Is a woman. & -0.532 \\
Bilingual Male & While abroad, spoke Japanese in the community. & \\
Eigenvalue =1.014 & &
\end{tabular}

Note: The items have been transformed from their original question form into statements to ease interpretation.

number of returnees, returned the questionnaires between November 1997 and March 1998, resulting in an approximately equal balance of both types of schools.

The university student sample came from seven universities, where packets were provided to the students directly from teachers. A university with a very large returnee population as well as those with fewer was selected. Non-student data were obtained from one cram school and three service organizations (i.e., Shijo tsuushin, Aloe no Kai, SIETAR Japan), selected because of their access to returnees who are no longer students. The newsletter "Shijo tsuushin" has approximately 400 subscribers, including many "older" returnees. "ALOE no Kai" is a group of mothers of returnees.

\section{Results}

\subsection{What are the social and psychological outcomes of the "returnee experience"? ( $R Q 1)$}

We conducted a principal components factor analysis (FA) on all of the variables measuring social and psychological outcomes, excluding items with open-ended responses and those where responses were conditional on affirmative responses to a previous item. Squared multiple correlations were used as communality estimates. To minimize sampling and response biases, prior to the FA we standardized all of an individual's 74 ratings to his or her own mean and standard deviation; then, we 
standardized all of the items to the group's mean and standard deviation on that item. This double standardization eliminated individual and group differences in the data set, while leaving interrelationships among the variables intact (van de Vijver \& Leung, 1997). Nine factors were extracted using eigenvalues $>1.00$ as the criterion for extraction, and cumulatively they accounted for $57.78 \%$ of the total variance. This criterion was selected because the scree plot did not reveal a clear break between meaningful and non-meaningful factors. Normal Varimax rotation was performed, and items with factor loadings $>0.30$ were considered loading on each factor (see Table 1). Interpretation of the items loading on each of the nine factors suggested the following names: Feeling Different (DV1), Self-Reflection/Expressiveness (DV2), Adjustment Difficulties (DV3), Acceptance (DV4), Advantage (DV5), Self-Affirmation (DV6), Negativity (DV7), Group Conformity (DV8), and Impact (DV9). Factor scores were then computed for each of these factors.

Hypothesis 1 stated that "feeling different" is a key factor in the returnee experience. The results of the FA supported this hypothesis, as the factor "feeling different" emerged as the first component in the analysis (eigenvalue $=3.502$ ).

Hypothesis la suggested that the social consequences of being different are rejection or acceptance by peers. This hypothesis was supported by the existence of Factor 4 (Acceptance).

Hypothesis $1 \mathrm{~b}$ suggested that possible personal attitudes of the returnees regarding feeling different are to conform or not to conform to the mainstream culture. Factor 8 (Group Conformity) supported this hypothesis.

Hypothesis 1c suggested that the psychological consequences of the returnee experience are adjustment problems and positive or negative assessment of the returnee experience. The psychological consequences that emerged from the FA included: Self-Reflection/Expressiveness (DV2), Adjustment Difficulties (DV3), SelfAffirmation (DV6), Negativity (DV7), and Impact (DV9). These factors were especially interesting in that they not only showed that returnees differed in their assessment of their experience (positive or negative), but that the relative impact of the experience also varied from individual to individual. For some it did not induce self-reflection nor did it have significant impact on their lives.

Hypothesis 2 examined whether the special provisions for the returnees created perceived advantages and/or stigma. DV5 (Advantage) showed that perceived advantage was a clear factor in defining the returnee experience.

In supporting Hypotheses 1 and 2, this study thus identified nine social and psychological outcomes of the returnee experience.

\subsection{Are there demographic and experiential characteristics that shape the experiences} of returnees while abroad and immediately upon return to Japan? (RQ2)

We conducted a principal components FA on the predictor items. Prior to this, all predictor items that involved three nominal categories as response alternatives were contrast coded into two variables. One item was dropped from the analysis (Which language did you speak at home?) because an overwhelming number of participants chose only one response (Japanese). The analysis also excluded open-ended 
responses and those items whose responses were conditional on affirmative responses to a previous item. Ten factors were extracted, using eigenvalues $>1.00$ as the criterion for extraction, and cumulatively they accounted for $66.1 \%$ of the total variance. Items with factor loadings $>0.30$ were considered loading on each factor (see Table 2). Interpretation of the items loading on each of the ten factors suggested the following factor names: Japanese School (IV1), International School (IV2), Extensive Stay (IV3), Communication with Parents (IV4), Special Provisions (IV5), Recency of Return (IV6), Older Sojourning Experience (IV7), International Community (IV8), Limited Resources (IV9) and Bilingual Male (IV10). Factor scores were then computed for each of the ten factors.

The first two factors that emerged, Japanese School and International School, highlighted the importance of the type of school attended while abroad. Extensive Stay (IV3) coincided with Minoura's (1988) and Takahagi et al.'s (1982) results that length of sojourn affects the returnee experience. Communication with Parents (IV4) indicated the degree to which parents talked to their children about many things, including the overseas assignment and return to Japan. Special Provisions (IV5) indicated that various provisions created for the returnees were defining features of the returnee experience. The emergence of Recency of Return (IV6) supported anecdotal evidence that recent returnees were different from those in the past (JOES, 1993 May). Older Sojourning Experience (IV7) supported Minoura's (1988) finding that age of sojourn was a significant factor.

Due to low eigenvalues and difficulty in interpretability, the last three factors should be viewed with care. The items loading on IV8 indicated that this factor included returnees who spoke English at school and in the community. Although not indicated in Table 2, the data also indicated that these returnees did not primarily attend a local school. With $98.4 \%$ of our respondents who lived in the United States having attended a local school, this suggested that these returnees lived in international communities in a country other than the United States. Limited Resources was so named because of the lack of jukus (private cram schools), unavailability of people to consult when faced with problems, compounded by the fact that these were individuals who returned many years ago when few resources were available to returnees. Although IV10 (Bilingual Male) indirectly supported Takahagi et al.'s (1982) and Gerner and Perry's (2000) contention that gender significantly affects the returnee experience, we found it interesting and perhaps puzzling that this was coupled with not speaking Japanese in the community. With $91.4 \%$ of our sample having spoken Japanese at home meant that this factor included those that were at least bilingual.

\subsection{Do the factors identified in $R Q 2$ predict the outcomes identified in $R Q 1$ ? (RQ3)}

To examine RQ3, a backward multiple regression was computed on each of the nine dependent variables identified earlier, using the $10 \mathrm{IVs}$ as initial predictors. All nine DVs were significantly predicted (see Table 3).

Hypothesis 3 stated that age, sex, length of sojourn, type of school attended upon return to Japan, place of sojourn and relationship with parents will predict the social 
Results of multiple regression analyses

\begin{tabular}{|c|c|c|c|c|c|}
\hline Factor & Predictor variables & $B^{\mathrm{a}}$ & SEB & $t$ & Significance \\
\hline $\begin{array}{l}\text { DV Factor 1: } \\
\text { Feeling Different } \\
R=0.381, R^{2}=0.145 \\
F(8,503)=10.686 \\
p<0.001\end{array}$ & $\begin{array}{l}\text { IV1 Japanese School } \\
\text { IV2 International School } \\
\text { IV4 Communication with Parents } \\
\text { IV6 Recency of Return } \\
\text { IV7 Older Sojourning Experience } \\
\text { IV8 International Community } \\
\text { IV9 Limited Resources } \\
\text { IV10 Bilingual Male }\end{array}$ & $\begin{array}{r}-0.198 \\
0.093 \\
-0.164 \\
-0.075 \\
-0.078 \\
-0.198 \\
-0.107 \\
-0.092\end{array}$ & $\begin{array}{l}0.041 \\
0.041 \\
0.041 \\
0.041 \\
0.041 \\
0.041 \\
0.041 \\
0.041\end{array}$ & $\begin{array}{r}-4.792 \\
2.259 \\
-3.975 \\
-1.825 \\
-1.902 \\
-4.802 \\
-2.584 \\
-2.223\end{array}$ & $\begin{array}{l}0.000 \\
0.024 \\
0.000 \\
0.069 \\
0.058 \\
0.000 \\
0.010 \\
0.027\end{array}$ \\
\hline $\begin{array}{l}\text { DV Factor } 2: \\
\text { Self-Reflection/Expressiveness } \\
R=0.294, R^{2}=0.087 \\
F(6,505)=7.971 \\
p<0.001\end{array}$ & $\begin{array}{l}\text { IV3 Extensive Stay } \\
\text { IV6 Recency of Return } \\
\text { IV7 Older Sojourning Experience } \\
\text { IV8 International Community } \\
\text { IV9 Limited Resources } \\
\text { IV10 Bilingual Male }\end{array}$ & $\begin{array}{l}-0.095 \\
-0.124 \\
-0.075 \\
-0.082 \\
-0.135 \\
-0.178\end{array}$ & $\begin{array}{l}0.043 \\
0.043 \\
0.043 \\
0.043 \\
0.043 \\
0.043\end{array}$ & $\begin{array}{l}-2.233 \\
-2.914 \\
-1.751 \\
-1.925 \\
-3.174 \\
-4.183\end{array}$ & $\begin{array}{l}0.026 \\
0.004 \\
0.081 \\
0.055 \\
0.002 \\
0.000\end{array}$ \\
\hline $\begin{array}{l}\text { DV Factor } 4: \\
\text { Acceptance } \\
R=0.261, R^{2}=0.068 \\
F(6,505)=6.164 \\
p<0.001\end{array}$ & $\begin{array}{l}\text { IV1 Japanese School } \\
\text { IV2 International School } \\
\text { IV4 Communication with Parents } \\
\text { IV5 Special Provisions } \\
\text { IV9 Limited Resources } \\
\text { IV10 Bilingual Male }\end{array}$ & $\begin{array}{r}-0.104 \\
-0.093 \\
0.119 \\
0.089 \\
-0.141 \\
-0.081\end{array}$ & $\begin{array}{l}0.043 \\
0.043 \\
0.043 \\
0.043 \\
0.043 \\
0.043\end{array}$ & $\begin{array}{r}-2.430 \\
-2.158 \\
2.780 \\
2.076 \\
-3.286 \\
-1.894\end{array}$ & $\begin{array}{l}0.015 \\
0.031 \\
0.006 \\
0.038 \\
0.001 \\
0.059\end{array}$ \\
\hline $\begin{array}{l}\text { DV Factor 5: } \\
\text { Advantage }\end{array}$ & $\begin{array}{l}\text { IV1 Japanese School } \\
\text { IV2 International School }\end{array}$ & $\begin{array}{l}-0.316 \\
-0.131\end{array}$ & $\begin{array}{l}0.040 \\
0.040\end{array}$ & $\begin{array}{l}-7.904 \\
-3.277\end{array}$ & $\begin{array}{l}0.000 \\
0.001\end{array}$ \\
\hline
\end{tabular}

Advantage

IV2 International School 


\begin{tabular}{|c|c|c|c|c|c|}
\hline$R=0.440, R_{2}=0.194$ & IV5 Special Provisions & -0.097 & 0.040 & -2.422 & 0.016 \\
\hline$F(7,504)=17.300$ & IV6 Recency of Return & -0.202 & 0.040 & -5.062 & 0.000 \\
\hline \multirow[t]{3}{*}{$p<0.001$} & IV7 Older Sojourning Experience & -0.095 & 0.040 & -2.369 & 0.018 \\
\hline & IV8 International Community & -0.101 & 0.040 & -2.518 & 0.012 \\
\hline & IV9 Limited Resources & -0.084 & 0.040 & -2.107 & 0.036 \\
\hline DV Factor 6: Self-Affirmation & IV4 Communication with Parents & 0.100 & 0.044 & 2.276 & 0.023 \\
\hline $\begin{array}{l}R=0.132, R^{2}=0.017 \\
F(2,509)=4.521 \\
p<0.01\end{array}$ & IV10 Bilingual Male & -0.086 & 0.044 & -1.965 & 0.050 \\
\hline DV Factor 7: & IV2 International School & -0.081 & 0.044 & -1.849 & 0.065 \\
\hline Negativity & IV3 Extensive Stay & -0.119 & 0.044 & -2.738 & 0.006 \\
\hline $\begin{array}{l}R=0.183, R^{2}=0.033 \\
F(3,508)=5.866 \\
p<0.01\end{array}$ & IV10 Bilingual Male & -0.113 & 0.044 & -2.585 & 0.010 \\
\hline DV Factor 8: Group Conformity & IV7 Older Sojourning Experience & -0.074 & 0.044 & -1.681 & 0.093 \\
\hline $\begin{array}{l}R=0.122, R^{2}=0.015 \\
F(2,509)=3.815 \\
p<0.05\end{array}$ & IV9 Limited Resources & -0.096 & 0.044 & -2.192 & 0.029 \\
\hline DV Factor 9: & IV3 Extensive Stay & -0.185 & 0.042 & -4.428 & 0.000 \\
\hline Impact & IV6 Recency of Return & 0.077 & 0.042 & 1.862 & 0.063 \\
\hline$R=0.343, R^{2}=0.117$ & IV8 International Community & -0.213 & 0.042 & -5.103 & 0.000 \\
\hline$F(4,507)=16.857, p<0.001$ & IV9 Limited Resources & -0.179 & 0.042 & -4.280 & 0.000 \\
\hline
\end{tabular}

${ }^{a}$ Beta scores were not listed because they were identical to the $B$ scores as we used factor scores (with orthogonal rotation) for the independent as well as dependent variables. 
and psychological outcomes identified in this study. All of these variables did, in fact, do that. For example, Older Sojourning Experience (IV7) predicted feeling less different, less self-reflection, less adjustment difficulties, less advantages and less of a tendency toward conforming to their peers. Sex (IV10-Bilingual Male), served as a predictor for seven out of the nine social and psychological outcomes. Bilingual males were less likely to feel different, spend time on self-reflection, experience adjustment difficulties, feel accepted, be self-affirming and be negative. Length of sojourn (IV3-Extensive Stay), predicted that those who spent more time abroad, went at an early age and lived in many countries, were less likely to spend time on self-reflection, were less likely to be negative, and were less likely to be impacted by the returnee experience. The type of school attended upon return to Japan (IV5Special Provisions), and those who attended schools with special provisions for returnees were less likely to experience adjustment difficulties, were more likely to feel accepted, and were more likely to enjoy the advantages of being a returnee. Place of sojourn (IV8-International Community), showed that those who lived in international communities were less likely to feel different, spend time on selfreflection, enjoy advantages of being a returnee, and be impacted by the returnee experience. Relationship with parents (IV4-Communication with Parents), predicted that those who communicated more with their parents were less likely to feel different and experience adjustment difficulties, and were more likely to feel accepted and score high on self-affirmation. Cumulatively, these findings provided strong support for Hypothesis 3.

Hypothesis 4 predicted that special provisions were likely to affect the returnee experience. Special provisions created for returnees included domestic as well as international changes, thus IVs 5 (Special Provision), 9 (Limited Resources), 1 (Japanese School) and 2 (International School) were examined. Furthermore, with many more facilities and special provisions currently available compared to 30 years ago, IV6 (Recency of Return) was also examined. As indicated above, IV5 (Special Provisions) served as a predictor for three of the nine outcomes. Those who had less access to special provisions (IV9: Limited Resources) were less likely to feel different, spend time on self-reflection, feel accepted, feel at an advantage, conform to the group and feel impacted by the returnee experience. Those who attended a Japanese School (IV1) were less likely to feel different, feel accepted, and feel that they were at an advantage. In contrast, those who attended International Schools (IV2) were more likely to feel different, and less likely to feel accepted, feel that they were at an advantage, and express negativity. Recency of Return (IV6) predicted feeling less different, less self-reflection, less adjustment difficulties, less advantages, but being impacted more by the experience. Thus, Hypothesis 4 was confirmed.

\section{Discussion}

This study reassesses the returnee experience in light of the various changes that occurred during the past 30 years. Results of the multiple regression analyses indicate that those who returned recently are less likely to feel different, spend time 
on self-reflection, experience adjustment difficulties, feel at an advantage, and are more likely to be impacted by the returnee experience. These findings are logical consequences of the fact that returnees are much less of an anomaly compared to before, and may reflect an increasing openness in Japanese society, and/or that recent returnees are better prepared for reentry. Another interpretation is that recent returnees are more Japanese and less foreign compared to those who returned earlier. A further interpretation is that recent returnees are more flexible than those in the past. These results confirm speculation that returning to Japan has become easier for recent returnees. What is a little puzzling is that recency of return also predicts a higher score on impact. In other words, the experience affects returnees' lives significantly even though they may not feel different or experience adjustment difficulties upon return to Japan.

The implementation of special provisions for returnees differentiates recent returnees from those who returned earlier. Results indicate that those who enjoy special provisions are less likely to experience adjustment difficulties or to feel at an advantage, and are more likely to feel accepted by their peers. It is encouraging to note that those who attend schools with special provisions for returnees were less likely to experience adjustment difficulties. This may be because such schools often host many returnees, and returnees can thus share their experiences with others like themselves. Furthermore, the non-returnee students at such schools are more likely to be accepting of returnees. Being one of many returnees, however, most likely reduces the feeling that they are special and are at an advantage.

Another purpose of this study was to uncover various demographic and experiential variables that predict subsequent social and psychological outcomes for returnees. Three outcomes that are of special interest to parents of returnees are: adjustment difficulties, acceptance and self-affirmation. It is interesting to note that a lower score on adjustment difficulties is predicted by communication with parents, special provisions, recency of return, older sojourning experience and bilingual male. This is encouraging news for parents of recent returnees, especially those who have taken the time to communicate with their children and have chosen to place their children in schools with special provisions for returnees.

It is equally interesting that a higher score on acceptance is predicted by not attending a Japanese school, not attending an international school, communicating with parents, special provisions, not having limited resources, and not being a bilingual male. Thus, communicating with parents and enjoying special provisions not only predicts lower scores on adjustment problems but also predicts a higher score on acceptance. Not attending a Japanese school and not attending an international school basically means that these returnees attended local schools. Attending a local school is synonymous to living in the United States; thus it can be inferred that living in the US predicts a higher score on acceptance. This finding makes sense because those who lived in the US would fit the stereotypical image of a returnee who is someone who grew up in the US and is bilingual in English and Japanese.

Communication with Parents is especially worthy of note, as it predicts a lower score on feeling different, adjustment difficulties and a higher score on acceptance 
and self-affirmation. These results show that respondents who communicate with their parents prior to, during and after their return to Japan are more likely to feel accepted upon return to Japan and are more likely to be satisfied with the returnee experience.

The current study was not conducted without limitations. First, the study relied on self-reports, which are not only subjective but are also likely to change over time; this may be a particular concern for those who returned quite some time prior to their participation in the study, because their data may be influenced by (re)construction of their memories over time. Another limitation may be sampling error. Because it is nearly impossible to locate returnees once they have graduated from college, the older returnee sample was obtained mainly through "Shijo Tsuushin," subscribers of which tend to be individuals who are still interested in the returnee issue long after their return to Japan. Finally, across all analyses, the regression coefficients were small in absolute standards; considering the sample size, however, we feel they were quite reasonable.

\section{Acknowledgements}

We would like to express our gratitude to the Mitsubishi Foundation for funding this research. We would also like to thank Melinda Wood for her invaluable comments on an earlier version of this paper. Last but not least, we would like to extend our sincere gratitude to the generous individuals who participated in our study.

\section{References}

Bock, P. K. (1977). Modern cultural anthropology: An introduction. New York: Alfred A. Knopf.

Chen, C., Lee, S., \& Stevenson, H. W. (1995). Response style and cross-cultural comparisons of rating scales among East Asian and North American students. Psychological Science, 6, 170-175.

Ebuchi, K. (1988). Impact of returning children from overseas upon education: Some comments on psychological studies of returnees from the standpoint of "internationalization" of Japanese schools. Shakai Shinrigaku Kenkyuu [Journal of Social Psychology], 3(2), 20-29.

Fichtner, D. (1988). A study of six variables affecting the perceived academic and social cross-cultural readjustment of returning Japanese high school students. Unpublished Doctoral Dissertation, University of Southern California, USA.

Fujiwara, K., Matsushita, M., Saito, J., Yamaki, T., Inoue, K., Koizumi, M., Mitsuhashi, M., Deguchi, Y., Kiuchi, K., Nagata, S., Ishige, H., Kasuya, I., Hirose, T., Nakamura, K., \& Koizumi, M. (1985). Psychological analysis of adjustment processes of the high school returnees from overseas. Bulletin of Tokyo Gakugei University Section I, 36, 871-881.

Gerner, M. E., \& Perry, F. (2000). Gender differences in cultural acceptance and career orientation among internationally mobile and non-internationally mobile adolescents. School Psychology Review, 29(2), 267-283.

Goodman, R. (1990). Japan's international youth: The emergence of a new class of school children. New York: Oxford University Press.

Iwawaki, S., \& Cowen, E. L. (1964). The social desirability of trait-descriptive terms: Applications to a Japanese sample. Journal of Social Psychology, 63, 199-205. 
Japan Overseas Educational Services [Kaigai Shijo Kyouiku Shinko Zaidan] (1993). Kikokushijo wa genki ka? [Are the returnees alive and well?]. Part 2. Kaigai Shijo Kyouiku [The Education of Children Overseas], 243, 17-23.

Kaigaishijo Kyouikushi Hensan Inkai (1991). Kaigaishijo kyouikushi [The history of the education of expatriate children]. Tokyo: JOES.

Kanno, Y. (2000). Kikokushijo as bicultural. International Journal of Intercultural Relations, 24, 261-382.

Kidder, L. H. (1992). Requirements for being "Japanese". International Journal of Intercultural Relations, 16, 383-393.

Kobayashi, T., et al. (1978). Zaigai kikokushijo no tekiou ni kansuru chousalhoukoku [A study of the adjustment processes of Japanese children overseas]. Kyoto Daigaku Kyouiku-gakubu Hikaku kyouiku Kenkyuushitsu [Kyoto University School of Education, Department of Comparative Education].

Kobayashi, T. (1983). Kaigai/Kikokushijo no tekiou [Adjustment of returnees]. Kyouiku Shinri [Journal of Educational Psychology], 31(5), 74-79.

Ministry of Education (Mombusho Kyoiku Joseikyoku) (1999). Kaigaishijo Kyoiku no Genjo [A report on the educational conditions of Japanese children overseas].

Minoura, Y. (1991). Kodomo no ibunka taiken [Children's intercultural experiences]: Tokyo: Shisou-sha.

Minoura, Y. (1988). The psychological reorganization of overseas experience after returning to Japan: A symbolic interactionist approach to returnees. Shakai Shinrigaku Kenkyuu [Journal of Social Psychology], 3(2), 3-11.

Onoda, E. (1988). Ibunka Taikensha toshite no "Kikokushijo" [Returnees as individuals who have experienced cross-cultural encounters]. Ibunka-kan Kyouiku [Intercultural/Transcultural Education], 2, $86-98$.

Takahagi, Y. et al. (1982). Kaigai/Kikokushijo ni okeru culture shock no youin bunseki to tekiou program no kaihatsu/shikou [An analysis of factors related to the returnees' culture shock and the development of an adjustment program] (No. 00445027). Tokyo Gakugei Daigaku Kaigai Shijo Kyouiku Center [The Center for Education of Children Overseas Tokyo Gakugei University].

Takeuchi, S., Imahori, T., \& Matsumoto, D. (2001). Adjustment of criticism styles in Japanese returnees to Japan. International Journal of Intercultural Relations, 25, 1-13.

Tamura, T., Inamura, H. (1987). Kaigaishijo/Kikokushijo no futekiou ni kansuru rinsho-teki kenkyu [Clinical research on the maladaptation of returnees]. Ibunka-kan Kyouiku [Intercultural/Transcultural Education], 1, 55-66.

Tsukamoto, M. (1990). Kaigai kara kikokushita kodomotachi no tekiou ni tsuite [Adjustment of children returning from abroad]. Kaigai Shijo Kyouiku [The Education of Children Overseas](January), 116-118.

Van de Vijver, F. J. R., \& Leung, K. (1997). Methods and data analysis for cross-cultural research. Newbury Park, CA: Sage.

White, M. (1988). The Japanese overseas: Can they go home again? Princeton, NJ: Princeton University. Zax, M., \& Takahashi, S. (1967). Cultural influence on response style: Comparisons of Japanese and American college students. Journal of Social Psychology, 71, 3-10. 